\title{
OFF-STREET PARKING CHOICE SENSITIVITY
}

\section{JOHN GOLIAS*, GEORGE YANNIS and MICHEL HARVATIS}

\author{
Department of Transportation Planning and Engineering, \\ National Technical University of Athens, 5 Iroon Polytechniou Street, \\ GR-157 73 Zografou, Athens, Greece
}

(Received 24 May 2000; Revised 6 November 2001; In final form 10 March 2002)

\begin{abstract}
This article deals with the determinants of choice between on- and off-street parking. In this context, a questionnaire-based survey was conducted and the stated preference method was used to develop an explanatory model. The model assessment showed that parking cost has, as expected, the most important impact on the choice of parking alternatives. Furthermore, all other variables with a significant impact on parking choice are time related, i.e., search time for a parking space, duration of parking and walking time from the parking space to the final destination. It is also shown that parking choice decisions did not depend on driver and trip characteristics. The methodology followed can be used in other similar cases for the identification of parking choice sensitivity, thus providing valuable input to the development of appropriate parking policy in a given area.
\end{abstract}

Keywords: Parking; Parking choice; Parking policy; Stated preference; Logit model

\section{INTRODUCTION}

In high density urban areas, especially city centres, there is strong competition for the use of space among the various urban activities: housing, economic activities, green space, traffic and parking. Public authorities are obliged to consult and arbitrate between the various possible competing uses for public space and to rank uses of each

\footnotetext{
*Corresponding author. E-mail: igolias@central.ntua.gr
} 
zone according to their importance for the local community (Poutanen, 1994). Parking is not only a political issue in urban planning and management, but also a key element of the policies used to facilitate trips and ameliorate traffic congestion. According to recent trends (Bayliss, 1999), parking policy appears to be the most promising means for travel demand management. By their effects on the potential for urban development, in the attractiveness of city centres and in the state of travel in the whole built-up area, parking policy parameters such as cost, lost time and parking availability are basic components of urban management schemes in modern cities (Vivier, 1997).

The importance of adopting and implementing a specific parking policy is also shown by the fact that a number of advanced systems are developed for the efficient implementation of the policy. New methods of payment are introduced, which by the use of cards (smart or not) facilitate the implementation of a specific parking strategy (Squires, 1999). The conventional and/or advanced systems for traffic management and parking guidance are creating new parking demand characteristics (Smith, 1999).

As a consequence, much current research is oriented towards the identification of the role of the various parameters affecting parking policies, especially those with an impact on drivers' choices. Weant and Levinson (1990) showed that the basic parameters considered in the design of parking schemes concern parking supply, parking fee rates, trip purpose, parking duration and walking distance. The examination of the interrelations between these parameters through targeted studies has led to a number of interesting quantitative findings for use by urban planners.

Research on the effects on modal split due to the restriction of parking availability (Gantvoort, 1984) demonstrated the dominant role of the latter in switching travellers from car to public transport, the bicycle or car-pooling. More precisely, before and after surveys concerning drivers' choices showed that the difficulty in finding a space is a more important factor than the increased parking fee. In addition, analysis of the revealed preference results showed that a walking distance from the parking space to the final destination of up to $800 \mathrm{~m}$ could be acceptable for drivers who insist on using their car. 
In an attempt to evaluate parking measures as a tool to alter modal split of workers in suburban business areas (Visser and Van der Mede, 1988), stated preference techniques were used and parameters with an impact on driver choice were identified separately for each transport mode. According to this research, the importance of parking fees compared to search time increases with actual travel time. Travel time is considered less important than search time, except for people with actual travel time of at least half an hour. Furthermore, in this research Visser et al. suggest that walking time from parking location to work appears to be less important than the time spent searching for a parking space.

It has also been shown that the components of parking policy could play an important role not only in transport mode choice but also in the choice among parking alternatives. According to a research study investigating the implications of a policy aiming to promote the shift from on-street parking to underground parking (EURONET, 1996), it appeared that most of the expected positive effects, such as the reduction of traffic nuisance, the facilitation of pedestrian mobility and the promotion of public transport, were not sufficient for drivers to abandon the use of their cars. Parking fee and space availability had more important impacts on drivers' choices.

According to a review of the impact of parking policy measures on travel demand (Feeney, 1989), parking policy variables have a substantial impact on the choice of parking location. In a research study examining parking impedance in different areas (Gur and Beimborn, 1984), the interrelation between the basic parameters of parking disutility (walking time, parking fee, penalty cost and search time) was calculated. By the use of an equilibrium assignment model, parking supply and demand were brought into balance and the relative role of each parameter to drivers' choice of parking location was calculated for a number of test cases.

Most of the above approaches are based on fixed assumptions about driver behaviour in response to changes in parking parameters and calculate future modal split and parking demand according to changes in parking parameter values. Using revealed or stated preference surveys, these approaches refer mainly to modal choice and parking characteristics rather than to choice between parking alternatives. 
The research reported in this article proposes the use of stated preference techniques so that, on the basis of models predicting driver behaviour, a reliable estimate of the split between on- and off-street parking can be achieved. In the absence of existing research in this specific area, off-street parking choice sensitivity constitutes an interesting research field for the investigation of the interrelation between the various cost and time parameters involved.

It is noted that stated preference techniques were originally developed in marketing research in the early 1970s (Green and Srinivasan, 1978), and have been widely used since the end of that decade in the marketing of new products (Louviere and Woodworth, 1983) and services as well as in the modal split of urban passenger transport (Hensher et al., 1988). Future market share between private cars and public transport in urban passenger transport systems is often predicted by models considering the stated preference of the users towards changing transport parameters (Hall, 1983; Louviere et al., 2000).

It should be noted that driver behaviour in relation to parking choices is complex and involves individual differences difficult to predict unless suitable models are developed (Polak, 1988). Thus, the outcome of this research could assist the development of parking strategies aiming to shift cars from on- to off-street parking in dense urban areas.

\section{FIELD SURVEY}

This research considers a part of the city centre of Piraeus, a major port city of about 500000 inhabitants located to the south-west of the Greater Athens area in Greece. In the area considered, intensive service and commercial activities co-exist together with residential buildings and recreation spaces. In order to identify the sensitivity of parking choice in relation to driver behaviour, a questionnaire-based survey with on-site interviews was carried out and the stated preference technique was used.

The sample was chosen randomly, as one out of five drivers coming to park or leaving the parking space at the survey area was questioned. In order to obtain a representative sample composition, the interviews 
were carried out on days with typical traffic conditions (Tuesday and Thursday). The time period covered was from 07:00 to 15:00 and from 16:30 to $20: 30$, so that parking demand variation related to various activities through the day is taken into account. The sample established by this survey is composed of 317 respondents.

The points where the interviews took place were carefully chosen so that the sample covered a variety of driver and trip characteristics, e.g., younger and older drivers, trip purpose, etc. The comparison of the sample characteristics with the main driver characteristics identified during the Athens general transportation study (Attiko Metro, 1997) shows that age groups are in fact satisfactorily covered as well as income and gender (at a 10\% level of significance). As far as trip characteristics are concerned, the ratio of frequent users to others is about 2 to 1 while when it comes to parking duration, 1 out of 3 drivers interviewed parked for less than four hours.

\section{THE QUESTIONNAIRE}

The interviews with the drivers in the study area were supported by a questionnaire specially designed for the survey. The questionnaire design allowed for the application of the A-logit model for the analysis (Pearmain and Kroes, 1990) and comprised of two parts. The first refers to the driver and trip characteristics: gender, age, income, trip purpose and trip frequency. Each driver was also asked his/her parking duration and the maximum time he/she was considering necessary for finding an on-street parking space. The second part of the questionnaire refers to driver behaviour in relation to parking and comprises of four sets with five cards each (Fig. 1).

Each card describes for a specific parking duration two parking scenarios, one on-street and one off-street. Realistic values for parameters describing each scenario are proposed to the drivers. These parameters are the necessary time for finding a parking space (equal to 0 for the case of off-street parking), the walking time in minutes between the parking space and the final destination and the cost (in drachmas (where 380 drachma $=1$ US\$)) the driver is required to pay for the specific parking duration. These parameters were chosen carefully to reflect the key elements of driver behaviour in parking, 


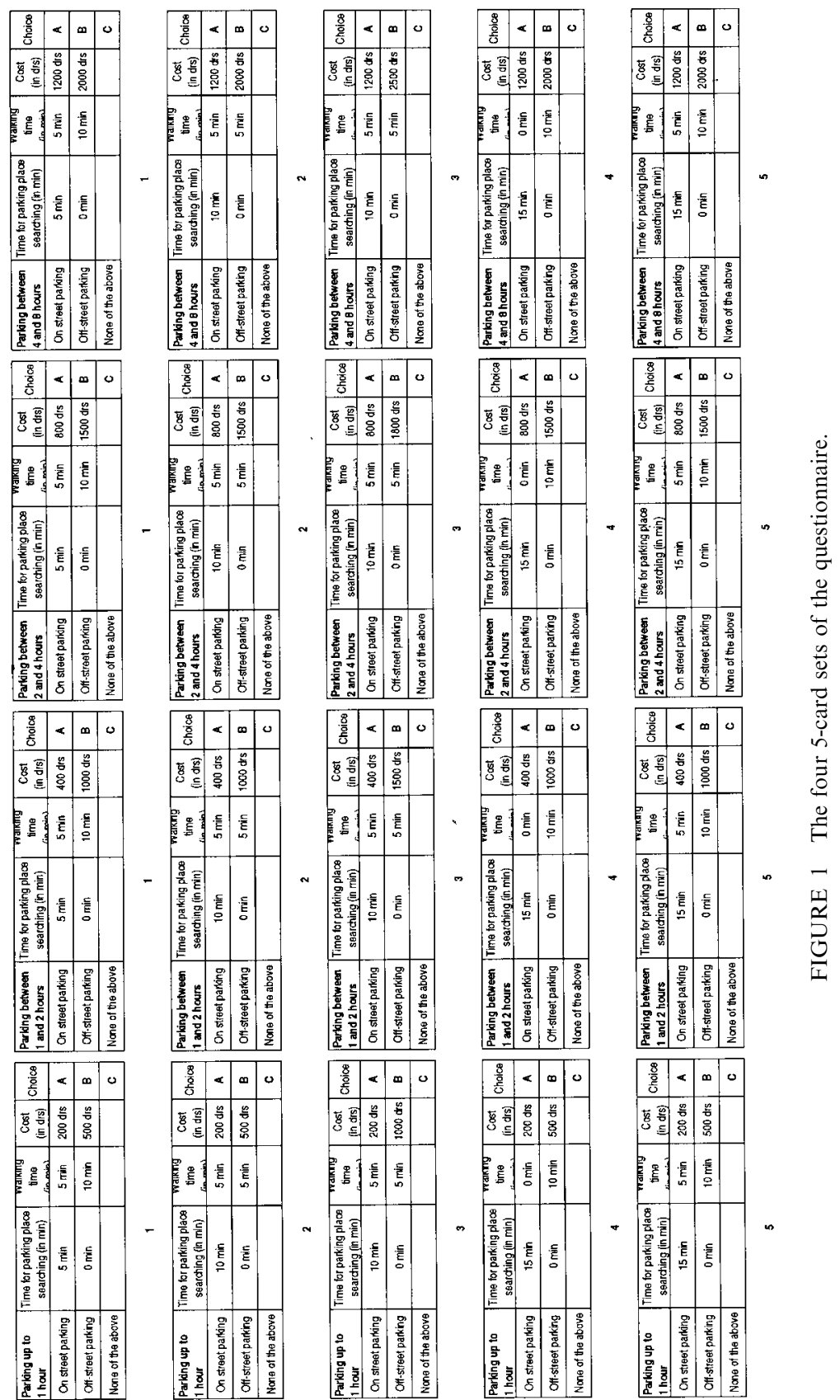


on the basis of previous surveys (Frantzeskakis et al., 1996; Vivier, 1997; Visser and Van der Mede, 1988). A third scenario is also proposed corresponding to the refusal of both of the above alternatives. On each card, each driver has to select one out of the three possibilities.

The four sets of cards related to the second part of the questionnaire correspond to four different parking durations. The first set refers to a parking duration of up to one hour, the second refers to a parking duration between one and two hours, the third refers to a parking duration between two and four hours and the fourth set refers to a parking duration of more than four hours. Following the response of each driver about the parking duration, the respective set of cards was filled in by the interviewer. The parking scenarios addressed by the different cards in the above four sets are given in Fig. 1.

\section{MODEL DEVELOPMENT}

In order to predict parking choice behaviour, an advanced model was developed. The model is the outcome of logit analysis, which is commonly employed in transport mode choice situations, to identify those parameters that are significant in affecting these choices. Other analytical methods also exist (probit, monanova, etc.) but for reasons of comparability, logit analysis was chosen in this work because it is very often used (Kroes and Sheldon, 1988) in similar cases and was also used in the Athens traffic study (Attiko Metro, 1997). Logit models can explain and predict many aspects of consumer behaviour, thus giving insights into the main variables determining consumers' current preferences, and allowing predictions about their future choices to be made (Louviere and Woodworth, 1983).

The input data for choice analysis models comes either from the observation of actual consumer choices (revealed preference data) or from the elicitation of responses to hypothetical choice scenarios (stated preference data). In the analysis of transport-related choices, the term stated preference refers to the use of individual respondents' statements about their preferences in a set of transport options (Kroes and Sheldon, 1988). These options are typically descriptions of transport situations or contexts constructed by the researcher. The more recently developed techniques allow stated preference analyses 
to move beyond the examination of preference structures to a direct examination of choice processes (Pearmain and Kroes, 1990). Although it is possible to elicit useful information by asking respondents to rank or rate the alternatives presented to them, it is usually considered preferable to put the questions in a behavioural choice context and ask for discrete choices (Hensher et al., 1988; Wardman, 1988).

The logit model developed in this research used the sample data obtained by the above mentioned questionnaire-based interviews. The data comprised (a) values of parameters assumed to have an impact on the choice of parking alternatives and (b) an indicator of the choice made by the interviewee.

Every driver has to choose among three different scenarios [on-street parking: option A, off-street parking: option B, refuse both options (i.e. will not use his/her car or will cancel his/her trip): option C] in each of the five cards proposed as described previously. If option $\mathrm{C}$ is chosen, i.e., if both options $\mathrm{A}$ and $\mathrm{B}$ are rejected, the data corresponding to this interview are not taken into account in the analysis. Furthermore, when the off-street parking alternative is chosen, it is supposed that this choice remains the same in cases where cost or walking time parameters are more advantageous than those of the chosen scenario. For example, suppose that the choice is made between the following scenarios described in Table I.

If the driver opts for choice $\mathrm{B}$, the parking cost is 1000 drachmas and it is supposed that he/she would also accept a cost less than 1000 drachmas. In this case, two observations enter in the statistical analysis as choice B is possible for 1000 drachmas and for 400 drachmas. On the contrary, if the driver opts for choice A, then only one observation is used in the analysis. This is due to the fact that the driver declares that he/she is willing to pay 400 drachmas but no information can be deduced for the intention to pay 1000 drachmas as a parking fee.

TABLE I Example of choice among alternative scenarios

\begin{tabular}{lcccc}
\hline $\begin{array}{l}\text { Parking } \\
\text { duration: } \\
1-2 \mathrm{~h}\end{array}$ & $\begin{array}{c}\text { Time to search } \\
\text { for a parking } \\
\text { space }(\mathrm{min})\end{array}$ & $\begin{array}{c}\text { Walking } \\
\text { time }(\mathrm{min})\end{array}$ & $\begin{array}{c}\text { Cost } \\
\text { (drachmas) }\end{array}$ & Choice \\
\hline $\begin{array}{l}\text { On-street parking } \\
\text { Off-street parking }\end{array}$ & 5 & 5 & 400 & $\mathrm{~A}$ \\
None of the above & 0 & 10 & 1000 & $\mathrm{~B}$ \\
\hline
\end{tabular}


Furthermore, walking time of choice B is less advantageous and it is assumed that search time for on-street parking cannot be 0 .

The data file produced on the basis of the above assumptions contains 3451 observations, which are used in the statistical analysis.

\section{THE VARIABLES CONSIDERED}

The variables considered in the model development procedure are shown in Table II. Part A of Table II shows the basic driver and trip characteristic parameters considered while part B refers to the basic parameters related to parking. By suitably combining some of the basic parameters, a number of composite variables that could have a satisfactory explanatory power for driver behaviour were derived. These variables are shown in part C of Table II.

TABLE II The basic variables considered

\begin{tabular}{ll}
\hline A. Basic parameters of driver & and trip characteristics \\
A: & Age groups (12-75 years old) \\
G: & Gender (male-female) \\
I: & Income group (high, medium, low) \\
P: & Trip purpose (return to residence, work, shopping, \\
F: & recreation, education, other) \\
B. Basic parameters related to parking \\
C: & Parking cost in drachmas (200-2500 drachmas) \\
D: & Duration of parking (up to one hour, one to two hours, \\
& two to four hours, more than four hours) \\
MTS: & Expected maximum on-street search time (15-20 min) \\
TW: & Walking time, between the parking space and the final \\
& destination $(0-10$ min) \\
TS: & Time for search time for parking space $(0-15$ min) \\
GTS: & Gain of time for parking space search, i.e., \\
& MTS-TS (0-20 min) \\
C. Composite variables & \\
C/D & TS + TW \\
C/I & GTS/(TS + TW $)$ \\
C/(D $\times$ I $)$ & GTS/TS \\
C/TW & TW/TS \\
C/TS & TW/GTS \\
C/(TS + TW $)$ & (TS + TW $) / G T S$ \\
C/GTS & \\
\hline &
\end{tabular}




\section{ANALYSIS}

Disaggregate binary logit models (Ben-Akiva and Lerman, 1985) were developed for the prediction of choice between parking alternatives. Given that there are only two alternatives, the utility of the on-street parking alternative is set equal to zero. The software used for the estimation of the utility function coefficients was the A-logit application (Hague Consulting Group, 1992).

The results of the above procedure also include the statistics for the evaluation of the goodness of fit of the model to the data as well as the significance of the variable coefficients in the model. The goodness of fit of the model is tested with the corrected $\rho^{2}$ index (Tardiff, 1976), which is given by:

$$
\rho^{2}=1-[1 *(\theta)] /[1 *(c)]
$$

where, $1 *(\theta)$ : is the maximum log-likelihood at convergence; $1 *(c)$ : is the log-likelihood at convergence of the constants only model (market share).

In trying to develop a reliable model the significance of the various variables considered, which are shown in Table II, was tested through iterative trials of model development. A variable was included in the model if the corresponding coefficient was significantly different from zero at the five percent level of significance or if the coefficient was not significant but the improvement to the likelihood function due to the inclusion of the variable was significant, as measured by the likelihood ratio (LR) test (Gunn and Bates, 1982; Horowitz, 1982; Ortuzar and Willumsen, 1990). Numerous different "paths" were tried in the context of these significance tests, operating the LR-test both "backward" to the null model and "forward" to the more complete model.

The model finally proposed on the basis of the above procedure includes the variables shown in Table III.

The inclusion of the ratio of the parking cost to the gain in time for parking space search (C/GTS) in the model seems to indicate that the impact of parking cost on off-street parking choice is closely related to the reduction of the time required to find a parking space. 
TABLE III Variables included in the proposed model

\begin{tabular}{ll}
\hline D: & Duration of parking \\
TW/GTS: & $\begin{array}{l}\text { Ratio of the walking time between the parking space and the } \\
\text { final destination to the gain of time for parking space search }\end{array}$ \\
C/GTS: & Ratio of the parking cost to the gain of time for parking space search \\
\hline
\end{tabular}

Furthermore, it is interesting to note that walking time between the parking space and the final destination is also assessed in relation to the reduction of the parking space finding time. More specifically, for offstreet parking the driver seems to rate equally walking time to search time savings implying thus that reluctance to walking is in general balanced by waiving uncertainty due to looking for a parking space.

During the model development procedure, the parameter coefficients were calculated and the $t$-test was carried out to measure the importance of each parameter in the driver choice of parking alternatives (Ortuzar and Willumsen, 1990; Hague Consulting Group, 1992). The variables finally included in the off-street parking utility function, $U_{P}$, as well as the values of the corresponding coefficients and the corresponding $t$-test values (in brackets) are given below. The value of $\rho^{2}$, expressing the goodness of fit of the model, is satisfactory and equal to 0.323 .

$$
\begin{gathered}
U_{p}=1.2940+0.2137 * \mathrm{D}-0.0512 *(\mathrm{TW} / \mathrm{GTS})-0.0056 *(\mathrm{C} / \mathrm{GTS}) \\
(7.2)
\end{gathered}
$$

\section{MODEL ASSESSMENT}

The sensitivity of off-street parking choice to the model parameters was investigated by assigning to each parameter values varying within the range which was used in the questionnaire. The selection of the value range for the questionnaire parameters was based on reasonable expectations concerning the off-street parking characteristics. The application of the various values to the model parameters led to the computation of off-street parking utility $\left(U_{P}\right)$, which was then used in the binary logit formula

$$
P_{P}=\exp \left(U_{P}\right) /\left[1+\exp \left(U_{P}\right)\right]
$$


to calculate the probability $\left(P_{P}\right)$ of choosing off-street parking. This probability expresses the percentage of drivers opting to use off-street parking.

The results of the model application for three different scenarios of choice between on- and off-street parking are presented in Table IV. One of the three scenarios adapts parameter values favourable for on-street parking, while a second focuses on off-street parking. The third scenario considers the intermediate case.

The value of each utility function parameter, the calculated value of off-street parking utility and the respective probability estimated by the binary logit formula are shown for every scenario in Table IV so that an indication of the results range to be expected is presented. It can be seen that depending on how favourable the parameter values are for off-street parking, the corresponding percentage may vary from about 1 to $90 \%$, i.e., it may cover the whole possible range.

Numerous combinations of parameter values were also applied to the model thus developed. Consideration of the results led to the extraction of a number of conclusions outlining some important characteristics of off-street parking choice sensitivity. These conclusions are summarised below.

It appears that parking cost has the most important impact on the choice of parking alternative. An increase in off-street parking cost leads as expected to a significant decrease of off-street parking share. This result is not surprising, as cost is very often the primary factor for the choice among two alternatives. It is however interesting to

TABLE IV Model application for three indicative parking choice scenarios

\begin{tabular}{|c|c|c|c|c|}
\hline & Coefficients & $\begin{array}{c}\text { Scenario } \\
\text { favourable } \\
\text { for on-street } \\
\text { parking }\end{array}$ & $\begin{array}{c}\text { Scenario } \\
\text { favourable } \\
\text { for off-street } \\
\text { parking }\end{array}$ & $\begin{array}{l}\text { Intermediate } \\
\text { scenario }\end{array}$ \\
\hline $\mathrm{C}$ (drachmas) & & 1000 & 2400 & 2400 \\
\hline TW (min) & & 8 & 1 & 4 \\
\hline GTS (min) & & 1 & 15 & 5 \\
\hline Constant & 1.294 & & & \\
\hline $\mathrm{D}(\mathrm{h})$ & 0.2137 & 1 & 8 & 4 \\
\hline TW/GTS & -0.05122 & 8 & 0.0667 & 0.800 \\
\hline C/GTS (drachmas/min) & -0.005585 & 1000 & 160 & 480 \\
\hline Off-street parking utility & & -4.4871 & 2.1066 & -0.5730 \\
\hline Off-street parking percentage & & $1.11 \%$ & $89.15 \%$ & $36.06 \%$ \\
\hline
\end{tabular}


note that off-street parking cost apart from being assessed in an absolute way is also assessed as cost per unit reduction in search time.

The time saving in finding a parking space also has an important impact on the market share of off-street parking. When on-street parking search time increases, the off-street parking attraction obviously increases too. This increase is more important when the time gained is up to ten minutes. The significance of reducing time spent in searching for a parking space is explained by the fact that searching is usually tiring and the uncertainty of finding a space has a direct negative impact on the psychology of the driver. Consequently, when this uncertainty increases, or when the time available to search for a parking space is limited, the market share of off-street parking increases accordingly.

The impact of parking duration on off-street parking market share is less important than the above parameters. It appears that off-street attraction increases as parking duration increases, although the opposite would be expected as a longer parking duration could justify a longer search time. However, the outcome of this research is explained by the fact that existing pricing policies - complex as they may be make, in any case, off-street parking cost more advantageous for longer parking periods. Furthermore, the above result can also be justified by the fact that off-street parking offers in general higher security, a factor that may be important for long period parking.

Finally, as far as walking time between the parking space and the final destination is concerned, it appears that the more drivers are obliged to walk, the less they choose off-street parking. This is an expected result not only because people may be physically reluctant to walk, but also because walking is interpreted as loss of time. However, the importance of the impact of walking time on the market share of off-street parking is less than that of the three variables described above.

\section{CONCLUSIONS}

The explanation of driver behaviour concerning choice of parking alternatives is not straightforward due to the complexity and variety of interactions involved. This research establishes links between a 
number of parameters and the choice between on- and off-street parking with the use of stated preference techniques. The model developed reveals that parameters which usually are taken into consideration in the more general framework of modal choice (cost, time, etc) also have an important impact on parking behaviour. The methodology proposed provides a more complete image of how parking choice decisions are taken and can offer better answers to the prediction of driver behaviour in the specific field of choice among parking alternatives.

A basic, though expected, finding of this research is the fact that parking cost has the most important impact on the choice of parking alternatives as the cheaper the parking alternative is the more attractive it becomes. Furthermore, it is interesting to note that all other variables with an impact on driver parking choice are time related: time for finding a parking space, duration of parking and walking time from the parking space to the final destination. Thus, time and cost seem to be dominant factors in the case of parking alternative choices too, as they are in all transport related choices. It is however interesting to note that both parking cost and walking time parameters are not assessed only in an absolute way but also in relation to the reduction of parking search time, which seems to be a point of reference for a number of driver parking decisions.

It is also worth noting that parking choice decisions do not depend on the characteristics of the driver and the trip (age, gender, income, trip purpose, trip frequency). It is however likely that some of these characteristics enter indirectly into the cost and time parameters related to the parking alternatives.

The model proposed is based on data referring to a typical part of the central business district of a rather large city. It is of course obvious that before this model is applied in other such areas, the existence of any peculiarities referring to parking behaviour should be carefully considered. In such cases, the methodology followed can be used for the identification of parking choice sensitivity. The results could be valuable for the design of an appropriate parking policy for a certain area, when the parking policy should necessarily comprise the number of off-street parking spaces required and the pricing policy to be adopted.

The improvement of parking conditions has a direct impact not only on the improvement of traffic conditions and road safety in the area 
considered, but also on the local economy. Consequently, the use of quantified results from the proposed methodology could assist in improving the design of the appropriate parking programme for a specific area and its implementation. The switch to off-street parking, which can free valuable road space to be better exploited, improving the overall quality of life of an area, can be achieved in a more secure way if the parameters influencing this switch as well as the magnitude of their effects are known.

\section{References}

Attiko Metro (1997) Athens Metro Development Study. Attiko Metro SA, Athens.

Bayliss, D. (1999) Parking Policies and Traffic Restraint in London. London Transport, London.

Ben-Akiva, M. and Lerman, S.R. (1985) Discrete Choice Analysis: Theory and Application to Travel Demand. The MIT Press, Cambridge-Massachusetts.

EURONET (1996) Lyon Parc Auto. Intégration d'une politique urbaine de stationnement. EURONET, Brussels.

Feeney, B.P. (1989) "A review of the impact of parking policy measures on travel", Transportation Planning and Technology 13(4), 229-244.

Frantzeskakis, I.M., Pitsiava-Latinopoulou, M. and Tsamboulas, D.A. (1996) Traffic Management, 182pp. National Technical University of Athens, Athens.

Gantvoort, J. (1984) "Effects upon modal choice of a parking restraint measure", Traffic Engineering and Control, 198-200.

Green, P.E. and Srinivasan, V. (1978) "Conjoint analysis in consumer research: issues and outlook", Journal of Consumer Research 5, 103-212.

Gunn, H.F. and Bates, J.J. (1982) "Statistical aspects of travel demand modelling", Transportation Research 16A(5), 371-382.

Gur, Y. and Beimborn, E. (1984) "Analysis of parking in urban centers: equilibrium assignment approach", Transportation Research Record 957, 55-62.

Hague Consulting Group (1992) ALOGIT Users' Guide Version 3.2. Hague Consulting Group, Cambridge, UK.

Hall, R.W. (1983) "Traveller route choice: travel time implications of improved information and adaptive decisions", Transportation Research 17A(3).

Hensher, D.A., Barnard, P.O. and Truong, P.T. (1988) The role of stated preference methods in studies of travel choice. Journal of Transport Economics and Policy, 45-58.

Horowitz, J.L. (1982) "Specification tests for probabilistic choice models", Transportation Research 16A(5), 383-394.

Kroes, E.P. and Sheldon, R.J. (1988) "Stated preference methods: an introduction", Journal of Transport Economics and Policy, 11-25.

Louviere, J. Hensher, D. and Swait, J. (2000) Stated Choice Methods: Analysis and Applications. Cambridge University Press, Cambridge, UK.

Louviere, J. and Woodworth, G. (1983) "Design and analysis of simulated consumer choice or allocation experiments: an approach based on aggregate data", Journal of Marketing Research, 350-367.

Ortuzar, J.D. and Willumsen, L.G. (1990) Modelling Transport. John Wiley and Sons, Chichester. 
Pearmain, D. and Kroes, E. (1990) Stated Preference Techniques: A Guide to Practice. Steer Davies \& Gleave Ltd. and Hague Consultancy Group, Cambridge, UK.

Polak, J. (1988) The analysis of central area parking management policies. Transport Policy: Proceedings of Seminar A (P303), 16th PTRC European Transport and Planning Summer Annual Meeting, pp. 81-93. University of Bath, England, September $12-16$.

Poutanen, O.P. (1994) Parking Policy Helsinki, Finland. Rupprecht Consult and Car Free Cities Network, Helsinki, Finland.

Smith, P. (1999) Fair Control, p. 60. TSP Europe, 2 April.

Squires, J. (1999) Dash from Cash, pp. 58-59. TSP Europe, 2 April.

Tardiff, T.J. (1976) "A note on goodness-of-fit statistics for probit and logit models", Transportation 5(4), 377-388.

Visser, J.J.C.M. and Van der Mede, P.H.J. (1988) The effects of parking measures on traffic congestion. Transport Policy: Proceedings of Seminar A (P303), 16th PTRC European Transport and Planning Summer Annual Meeting, pp. 95-107. University of Bath, England, September 12-16.

Vivier, J. (1997) Politique de stationnement. Etat de l'Art-Propositions de l'UITP, 17pp. Centre de Documentation de l'UITP.

Wardman, M. (1988) "Comparison of RP and SP models of travel behaviour", Journal of Transport Economics and Policy, 71-91.

Weant, R. and Levinson, H. (1990) Parking. Eno Transportation Foundation, Lansdowne, Virginia. 